\title{
ENFERMARÍA COMUNITARIA I DURANTE A PANDEMIA COVID-19
}

\author{
Fernández Basanta, Sara'; Coronado Carvajal, Carmen² \\ ${ }^{1}$ Universidade da Coruña, Facultade de Enfermería e Podoloxía, \\ https://orcid.org/0000-0002-7542-9667 \\ 2Universidade de Coruña, Facultade de Enfermería e Podoloxía, \\ https://orcid.org/0000-0002-4824-6902
}

\section{RESUMO}

No curso académico 2019-20 a materia Enfermaría Comunitaria I estaba programada para desenvolverse en tres talleres de docencia interactiva en grupos de 20 estudantes. Sen embargo, a pandemia do COVID-19 obrigou a transformar esta docencia a non presencialidade. Durante os seminarios o alumnado realizou lecturas relacionadas coa temática do seminario, e dinámicas de debate de grupo posterior en grupos pequenos, utilizado a ferramenta TEAMS. Ademais, foron utilizados dous cuestionarios de carácter voluntario para a avaliación do impacto da aprendizaxe. Estes cuestionarios foron cubertos polo estudiantado no inicio e o final da proposta educativa. A incorporación do coidado na diversidade funcional nos contidos da materia proporcionou os/as estudantes ferramentas de reflexión sobre este concepto, a súa relación coa enfermaría e os coidados, e a súa futura práctica profesional. Os contidos e actividades deseñadas permitíronlles ampliar os seus coñecementos e ser conscientes que as desigualdades están presentes na súa contorna, así como integrar unha perspectiva holística, plural e transcultural no seu futuro traballo co individuo, familia e comunidade.

PALABRAS CLAVE: Desigualdade funcional; Docencia telemática, Enfermaría comunitaria 


\section{CITA RECOMENDADA:}

Fernández Basanta, Sara; Coronado Carvajal, Carmen (2021): Enfermaría Comunitaria I durante a pandemia COVID-19. En García Naya, J.A. (ed.) (2021). Contextos universitarios transformadores: a nova normalidade académica. Leccións aprendidas e retos de futuro. V Xornadas de Innovación Docente. Cufie. Universidade da Coruña. A Coruña (pág. 169-180).

DOl capítulo: https://doi.org/10.17979/spudc.9788497498180.169

DOI libro: https://doi.org/10.17979/spudc.9788497498180

\section{ABSTRACT}

Community Nursing I was scheduled to develop in three interactive teaching workshops in groups of 20 students in the academic year 2019-20. However, the COVID-19 pandemic forced this teaching to be transformed into non-attendance. During the seminars the students made readings related to the topic of the seminar, and dynamics of group discussion, using TEAMS. In addition, two voluntary questionnaires were used to assess the impact of learning. These questionnaires were completed by the students at the beginning and end of the educational proposal. The incorporation of care in functional diversity in the contents of the subject has provided students with tools for reflection on this concept, its relationship with nursing and care, and their future professional practice. The contents and activities designed allowed them to expand their knowledge and be aware that inequalities are present in their environment, as well as integrate a holistic, plural and cross-cultural perspective in their future contact with the individual, family and community.

KEY WORDS: Functional inequality; Virtual teaching; Community nursing 


\section{DESCRICIÓN DA EXPERIENCIA}

A materia Enfermaría Comunitaria I, a cal cursase no segundo cuadrimestre do segundo curso do Grao de Enfermaría, ten asignados 1,5 créditos para a competencia específica de Comprender a saúde e identificar e analizar os factores determinantes da saúde (biolóxicos, ambientais, estilos de vida, e sistema sanitario).

No curso académico 2019-20 a materia anteriormente citada estaba programada para desenvolverse tres talleres de docencia interactiva en grupos de 20 estudantes, de hora e media de duración. Sen embargo, a pandemia do COVID-19 obrigou a transformar esta docencia a non presencialidade. Realizáronse lecturas e dinámicas de debate de grupo posterior en grupos pequenos e utilizado a ferramenta TEAMS. Tras isto, os e as estudantes elaboraron materiais dixitais que se compartiron a totalidade do grupo a través da aula virtual Moodle.

As lecturas foron organizadas en tres seminarios de acordo a tres grandes temáticas: Perspectiva de xénero e saúde, ambiente e saúde, e estilos de vida e saúde, onde a tematica de diversidade funcional foi transversal a estes grupos. 0 primeiro seminario sobre a perspectiva de xénero contivo catro lecturas (Artacoz et al., 2018; Borrel et al, 2004; Norrel e Artacoz, 2008; Catalán e Talavera, 2012). As lecturas do segundo seminario foron relativas ó ambiente e saúde (Agencia Europea de Medio Ambiente, 2018; Kazmierczak, 2019; Organización Mundial de la Salud, 2016; Prüss-Ustün, Corvalán, e WHO, 2006; United States EPA, 2019; Veliz-Rojas et al., 2019). Finalmente, as lecturas contidas no seminario tres pertencían a temática de estilos de vida e saúde (Gras, 2013; Jiménez Rodrigo, 2010; Organización Mundial de la Salud, 2010; Organización Mundial de la Salud, 2015; Organización Mundial de la Salud, 2020; Pino e Pérez, 2011).

Ademais, foron utilizados dous cuestionarios de carácter voluntario para a avaliación do impacto da aprendizaxe. Estes cuestionarios foron cubertos polo estudiantado en dous momentos. Un inicial diagnóstico (C1) que contía tres preguntas abertas, e que os estudantes 
entregaron 0 inicio da proposta educativa, mentres que cuestionario final avaliativo (C2) foi cuberto polos estudantes o finalizala. Este último cuestionario incluía ademais unha cuarta pregunta aberta e outro cuestionario de trece preguntas pechadas de tipo Likert, codificadas entre 1 e 5 (Totalmente En Desacordo =1; En Desacordo =2; Ni En Desacordo Ni De Acordo $=3$; De Acordo $=4$; Totalmente De Acordo $=5$ ), co obxectivo de avaliar a satisfacción dos participantes nesta actividade docente, en canto a planificación, desenvolvemento, resultados e coordinación/teorización da mesma. Unha vez entregados, os cuestionarios foron anonimizados e codificados cun código alfanumérico (C1 ou C2, segundo fose cuestionario inicial ou final, e o código do estudante).

Os datos obtidos dos cuestionarios foron analizados seguindo metodoloxías descritivas cuantitativas e cualitativas (Hernández-Sampieri e Mendoza Torres, 2018).

\section{RESULTADOS}

0 número de participantes no cuestionario de avaliación foi de 40 estudantes da totalidade de 62 matriculados na materia de Enfermaría Comunitaria I do Grao de Enfermaría no curso académico 2019-2020.

0 ítem 3 do cuestionario de avaliación fai fincapé nos resultados de aprendizaxe do alumnado respecto a actividade proposta. A táboa 1 mostra a puntuación media e a desviación estándar das preguntas relativas a este apartado

\begin{tabular}{|l|c|c|}
\hline \multicolumn{1}{|c|}{ Preguntas } & $\begin{array}{c}\text { Puntuación } \\
\text { media }\end{array}$ & $\begin{array}{c}\text { Desviación } \\
\text { típica estándar }\end{array}$ \\
\hline $\begin{array}{l}\text { A actividade fíxome consciente de problemas complexos da } \\
\text { comunidade e lévame a pensar en desigualdades en saúde }\end{array}$ & 4.8 & 0.46 \\
\hline $\begin{array}{l}\text { Os seminarios axudáronme a entender a relación das persoas } \\
\text { co Medio Ambiente e os Estilos de Vida dende unha } \\
\text { perspectiva de diversidade }\end{array}$ & 4.7 & 0.49 \\
\hline $\begin{array}{l}\text { Aplicar a perspectiva de diversidade animoume a comprender } \\
\text { mellor o meu rol e responsabilidade como cidadán e futuro } \\
\text { profesional sanitario }\end{array}$ & 4.9 & 0.30 \\
\hline
\end{tabular}

Táboa 2 Resultados do cuestionario de avaliación respecto a satisfacción coa actividade académica 
*Asignouse 0 valor de 1 á resposta Totalmente en Desacordo e 5 a resposta Totalmente De Acordo

A figura 1 mostra a distribucións de resposta dos/as estudantes participantes no cuestionario de avaliación. Respecto a pregunta $A$ actividade fíxome consciente de problemas complexos da comunidade e lévame a pensar en desigualdades en saúde 0 83\% dos estudantes participantes estaban totalmente de acordo. 0 98\% estiveron de acordo ou totalmente de acordo respecto a que "os seminarios lles axudaron a entender a relación das persoas co Medio Ambiente e os Estilos de Vida dende unha perspectiva de diversidade". 0 100\% indicou a súa responsabilidade de aplicar a perspectiva de diversidade como futuro profesional da saúde.

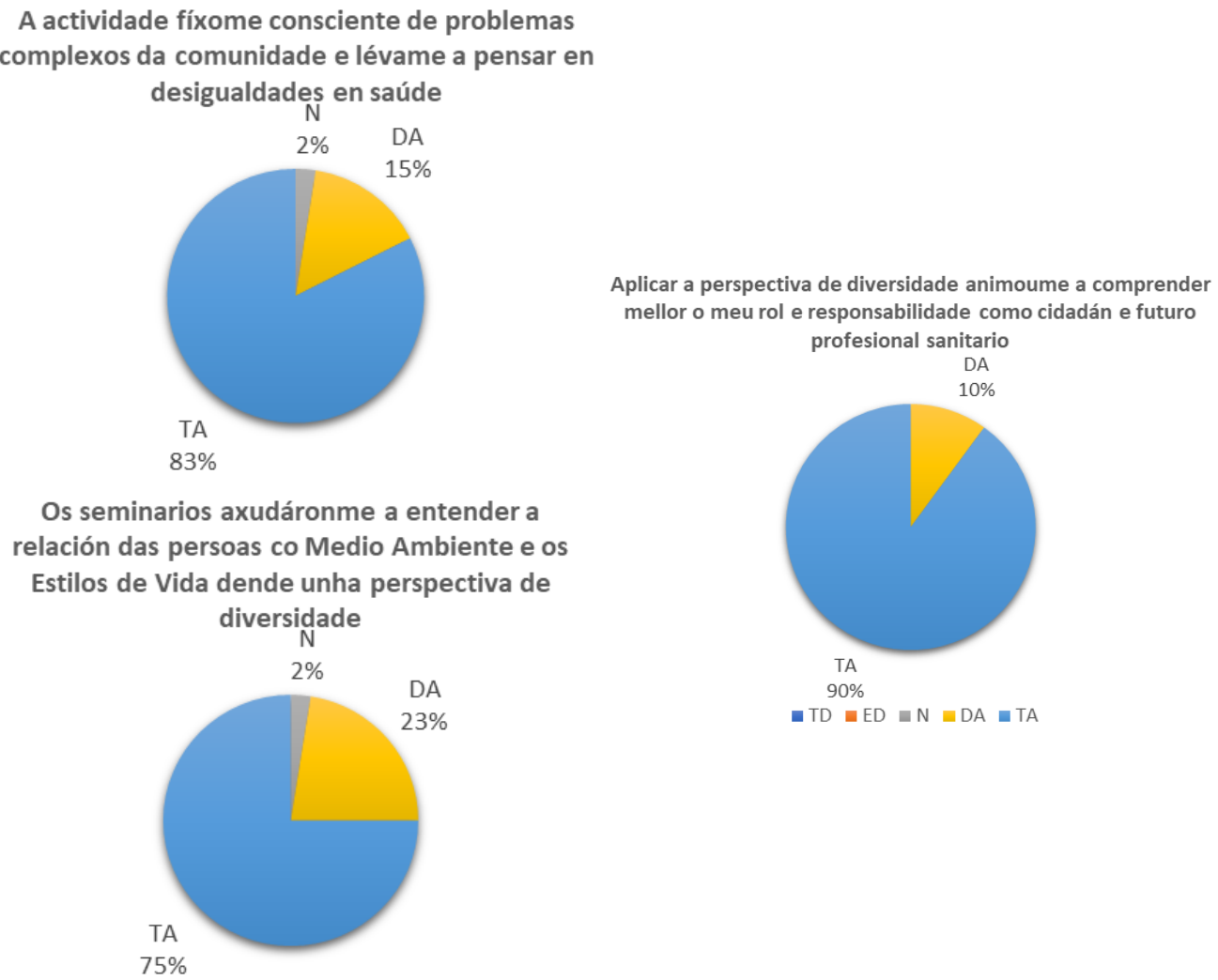

*TD, totalmente en desacordo; ED, en desacordo; N, neutro; DA, de acordo; TA, totalmente de acordo Figura 1 Distribución das respostas dos/as estudantes as preguntas do cuestionario de avaliación 
A continuación, presentasen os resultados cualitativos obtidos das respostas do alumnado. Dunha mostra total de 62 estudantes, 54 estudantes participaron no cuestionario inicial e no cuestionario final responderon 41 alumnos/as (unha persoa só respondeu as preguntas abertas do cuestionario).

Respecto a pregunta unha, Que entendes por coidar na diversidade?, o alumnado entendeu a diversidade como variedade en canto a diversas variables: raza, sexo, xénero, idade, crenzas, valores, posición social, nivel económico, presencia de enfermidades, funcionalidade, relixión, e nacionalidade. Esta diversidade foi relacionada co coidado como un coidado individualizado, integral, plural, non discriminatorio e non xerador de barreiras.

Atender os coidados necesarios para o individuo tendo en conta os aspectos socioculturais, valores, crenzas, a súa concepción da saúde e a enfermidade, o seu modo de vida e calquera outro aspecto que marque a súa diversidade cultural, é dicir, atender a súa saúde dende unha perspectiva integradora e comprensiva das súas características culturais (C1-E57)

Entendo por coidar na diversidade o feito de proporcionar o paciente os coidados e axuda que poida necesitar, adaptándose a súas necesidades. Hoxe en día encontrámonos con moitos casos diferentes de patoloxía, estilos de vida, costumes, relixións ou simplemente desexos, e cada unha delas pode necesitar dunha maneira ou outra os coidados, por iso sempre que este na nosa man e sexa posible adaptarémonos a estas diversas necesidades. Non fai falta mencionar que o persoal sanitario respectará en todo momento e proporcionará os mesmos coidados indiferentemente da raza, o sexo, a orientación sexual, la nacionalidade, os valores, as crenzas, etc. (C1-E38)

Como profesionais que vamos ser dos coidados, nunca debemos de auto limitarnos a hora de ofrecer a nosa labor, escudándonos en aspectos sociais ou morais. (C2E62) 
Adaptar os recursos sanitarios dispoñibles entre unha poboación determinada nun determinado momento a grupos minoritarios, que por este motivo poden verse excluídos en ocasiones, da promoción, prevención e curación sanitaria. (C2-E42)

Na maioría dos casos, mantivéronse as definición iniciais no cuestionario de avaliación. Sen embargo, un grupo de estudantes resaltaron que a actividade académica outorgoulles unha visión más ampla do concepto de coidar na diversidade. Concretamente, sinalaron que sendo conscientes da diversidades e xunto coa súa propia contribución contribúese a reducir as desigualdades en saúde.

Dende unha visión máis ampla, agora vexo o coidado da diversidade como proporcionar servicios adecuados as características concretas de cada persoa, incluíndo a todo individuo independentemente da súa raza, sexo... (C2-E49)

Tras completar esta parte da materia, entendo que coidar na diversidade, fai referencia a atender e ter en conta as diferencias en saúde que se producen de forma sistemática e que son resultado das diferentes oportunidades e recursos que teñen as persoas en función da súa capacidade, clase social, educación, posición económica, sexo, territorio ou raza. (C2-E37)

Na pregunta 2, 0 alumnado foi preguntado acerca de como crían que a diversidade pode condicionar a saúde das persoas. Entre as respostas dadas no cuestionario inicial e 0 final non houbo grandes diferenzas, aínda que nalgún casos que mostraron unha resposta mais limitada no cuestionario inicial, e a participación na actividade académica permitiulles reflexionar sobre outros aspectos que non foron considerados previamente. Ademais, tamén comentaron que as lecturas permitíronlles ser conscientes que as desigualdades en saúde tamén están presentes no seu contexto.

[...] Trala lectura do temario e do material complementario gustaríame engadir que hai outros factores que tamén considéranse diversidade e que afectan de distinta 
maneira a saúde das persoas, por exemplo, o medio ambiente no que se encontran e o estilo de vida enfocado a alimentación, o exercicio físico e os hábitos. (C2-E31)

Por un lado, mencionaron os diversos condicionantes que inflúen na saúde.

Son moitos os factores que poden condicionar a saúde das persoas. Dende o noso entorno, a diversos niveis, tales como; ecolóxicos e medioambientais (contaminación, radiacións, ruído, catástrofes...), xeográficos e demográficos (tanto a nivel estático, como dinámico), sistemas sanitarios (organización, acceso, prestacións), socioculturais (crenzas, economía, cultura, tradicións, sexualidade, lingua...), ata un nivel individual, biolóxico (factores xenéticos, ciclo de vida, etnias, hábitos...) (C1-E20)

A cultura e entorno social foi visto como o principal condicionante. Este factor repercute na construción da saúde e enfermidade de cada persoa, os cales deben ser consideradas e integradas no coidado.

Os profesionais sanitarios cada día teñen maior diversidade de pacientes, que chegan de diferentes lugares e características distintas, incluso procedentes de culturas diversas, polo que é necesario coñecer as costumes e crenzas de dito paciente para abordar de mellor maneira o problema de saúde, e necesario comprendelos dende a súa perspectiva, do que é a saúde e a enfermidade para estas persoas para conseguir unha mellor relación persoa a persoa con eles. (C1-E6)

Noso deber é coñecer os condicionantes do paciente contextualizándoos na súa propia cultura, relixión, crenzas... entendendo que é para eles a "saúde" e a "enfermidade", para poder axudarlles da mellor maneira posible. (C2-E22)

[...] debido a culturas ou diversas crenzas, a persoa pode negarse a recibir certos tratamentos, como pode ser transfusións de sangue. (C2-E60) 
Ademais, resaltaron que factores socioculturais actuais son xeradores de desigualdades en saúde e discriminación, e que o sistema actual potencia esas desigualdades.

La diversidad condiciona la salud de las personas. No todo el mundo puede acceder de la misma forma al sistema sanitario, puede permitirse comprar ciertos fármacos, expresa sus problemas de la misma forma en consulta o recibir tratamientos específicos debido a sus creencias y valores. Si no tenemos en cuenta la diversidad, podemos generar conflictos a las personas que cuidamos, tanto en su salud física, psicológica como en su vida social. (C1-E9)

A terceira pregunta do cuestionario fai referencia a se eles/elas cren que as intervencións sanitarias deben ter en conta a diversidade, e cales son as razón para apoiar esa afirmación. No cuestionario inicial a meirande parte dos participantes apoiaron a inclusión da diversidade nas intervención sanitarias, e no final a totalidade dos participantes.

Por suposto, para garantir uns coidados de calidade debemos ver a persoa como un todo, por elo debemos ter en conta toda a súa situación e necesidades. (C1-E47)

Non existe un coidado universal, xenuíno, os coidados deben estar abertos a diversidade, a todas as visións, as maiorías e as minorías. (C1-E42)

As persoas son seres inseparables da súa cultura e por elo, todas as intervencións de enfermaría deben responder os seus valores e crenzas. 0 contrario, nos acercaría (perigosamente) 0 arcaico modelo paternalista que cousificaba o paciente e separaba a súa realidade individual da enfermidade física. Non podemos pedirlle o enfermo que deixe a súa diversidade fora da consulta, porque ignoraríamos unha parte fundamental da súa saúde que nos impediría alcanzar o éxito terapéutico. En ocasións, a rixidez do sistema sanitario despersonaliza os enfermos e personifica as enfermidades, (C1-E61) 
Algún deles/delas matizaban que esas intervencións sanitarias diversas debían ser non discriminatorias respecto as minorías.

En cuestións de raza por exemplo, non creo que hai que facer distincións, todos somos persas, sexamos da raza, relixión ou cultura que sexamos. (C1-E3)

Entre as razóns que alegaron para apoiar a inclusión da diversidade destacaron a evitación de vulneración de dereitos e ética profesional, e de exclusión de persoas inmigrantes, racismo e calquera forma de discriminación, así como a contribución para acadar unha saúde universal. Outras foron a promoción da inclusión e integración social, a mellora da adherencia do/da paciente os tratamentos ó afianzar o vinculo cos profesionais sanitarios.

Finalmente, o cuestionario final incluía unha pregunta acerca da utilidade dos coñecementos adquiridos durante a intervención académica para dirixir intervencións sanitarias tendo en conta a diversidade dun/dunha paciente. A totalidade do alumnado estivo de acordo e resaltaron que tras a intervención académica foron conscientes do concepto de diversidade nun sentido mais amplo e próximo a súa realidade.

Os coñecementos adquiridos deixáronme ver de forma máis ampla os problemas que hai no trato da diversidade e as posibles maneiras nas que os sanitarios podemos influír para mellorar este trato. (C2-E49)

Antes de cursar esta materia meus coñecementos eran moi básicos, tanto que solo consideraba diversidade ó sexo, idade ou raza. Despois de lerme os temas vexo que é moito máis. (C2-E47)

Creo que axudará nas miñas futuras intervencións profesionais, concibindo ó paciente como un individuo que padece a influencia de factores ou variables, externos ou internos, que modificarán a súa saúde e calidade de vida. (C2-E32)

Tras realizar as lecturas dos seminarios fun consciente de que me estaba esquecendo de cuestións como a discapacidade, o clima, as adiccións e o poder económico que son conceptos moi claves a ter en conta na saúde das persoas. (C2-E21) 


\section{CONCLUSIÓNS}

A incorporación da diversidade os contidos da materia Enfermaría Comunitaria I proporcionou os/as estudantes con ferramentas de reflexión sobre este concepto, a súa relación coa enfermaría e os coidados, e a súa futura práctica profesional. Os contidos e actividades deseñadas para isto permitíronlles ampliar o seus coñecementos e ser conscientes que as desigualdades están presentes na súa contorna, así como integrar unha perspectiva integral, plural e transcultural no seu futuro traballo co individuo, familia, comunidade.

\section{REFERENCIAS}

Agencia Europea de Medio Ambiente (2018): Un aire más limpio beneficia la salud humana y contribuye a combatir el cambio climático, Agencia Europea de Medio Ambiente, Copenhagen (Dinamarca)

Artazcoz, L., Chilet, E., Escartín, P., \& Fernández, A. (2018). Incorporación de la perspectiva de género en la salud comunitaria. Informe SESPAS 2018. Gaceta Sanitaria, 32, 92-97. Borrell, C., García-Calvente, M. D. M., \& Martí-Boscà, J. V. (2004). La salud pública desde la perspectiva de género y clase social. Gaceta sanitaria, 18(4), 02-06.

Borrell, C., \& Artazcoz, L. (2008). Las desigualdades de género en salud: retos para el futuro. Catalán, V. G., \& Talavera, M. (2012). La construcción del concepto de salud. Didáctica de las ciencias experimentales y sociales, (26).

Gras, L. (2013). Imagen corporal, identidad de género y alimentación. Dossiers Feministes, $17,99-104$

Hernández-Sampieri, Roberto e Mendoza Torres, Christian Paulina (2018): Metodología de la investigación, McGrawHill Education, Ciudad de México

Jiménez Rodrigo, M. L. (2010). Consumos de tabaco y género. EGUZKILORE, (24), 71-95

Kazmierczak, A. (2019). ¿Cómo afectan los peligros medioambientales a los grupos vulnerables en Europa? Boletín de la AEMA 
Organización Mundial de la Salud. (2010). Estrategia mundial para reducir el uso nocivo del alcohol.

Organización Mundial de la Salud. (2015). Informe OMS sobre la epidemia mundial de tabaquismo, 2015: Aumentar los impuestos al tabaco. Organización Mundial de la Salud. Ginebra (Suiza)

Organización Mundial de la Salud. (2016). Género, cambio climático y salud. Organización Mundial de la Salud, Ginebra (Suiza).

Organización Mundial de la Salud. (2020). Discapacidad y salud. Organización Mundial de la Salud, Ginebra (Suiza). Disponible en: https://www.who.int/es/news-room/factsheets/detail/disability-and-health

Pino, F. J. B., \& Pérez, J. I. A. (2011). Pobreza, discapacidad y dependencia en España. Papeles de economía española, (129), 14-26.

Prüss-Ustuin, A., Corvalán, C. F., \& World Health Organization. (2006). Ambientes saludables y prevención de enfermedades: hacia una estimación de la carga de morbilidad atribuible al medio ambiente: resumen de orientación.

United States Environmental Protection Agency (EPA). (2016) El cambio climático y la salud de las personas con discapacidad. Lifestage Environmental Exposures and Disease (MLEEaD).

Disponible

en:

http://ehscc.umich.edu/Files/EPA_Climate_Change_Materials/disabilities-health-climatechange-sp.pdf

Veliz-Rojas, L., Bianchetti-Saavedra, A. F., \& Silva-Fernández, M. (2019). Competencias interculturales en la atención primaria de salud: un desafío para la educación superior frente a contextos de diversidad cultural. Cadernos de Saúde Pública, 35. 